\title{
Reutilización de los edificios patrimoniales. ¿Re-significación de la memoria?
}

Reutilização dos edifícios patrimoniais. Ressignificação da memória?

Reuse of heritage buildings. Re-significance of memory?

Jenny González Muñoz

\section{Resumen}

El presente artículo pretende llevar al lector hacia la reflexión sobre la reutilización de los edificios patrimoniales siendo estos lugares de memoria tanto histórica como colectiva y social, de los pueblos a los que pertenecen. Con ejemplos específicos en casos de países como Uruguay, México y Venezuela, se desarrolla un breve análisis sobre lo conveniente o no de la intervención de la arquitectura original de los edificios como lugares de memoria para continuar luego planes de nuevas perspectivas de uso muchos de los cuales no siempre están vinculados con lo cultural, lo cual apunta a una suerte de agresión a la identidad y sentido de pertenencia de la comunidad hacia dichos edificios. Se aboga también hacia la salvaguarda, conservación y protección de los edificios patrimoniales como lugares de memoria.

Palabras clave: Lugares de memoria. Memoria. Nuevos usos. Patrimonio material.

\section{Procesos memoriales en la construcción social}

En 1927, Maurice Halbwachs habla de la existencia de los cuadros sociales de la memoria y posteriormente de la memoria colectiva, producto de recuerdos que pertenecen, de una $\mathrm{u}$ otra manera, a personas que forman un mismo grupo. La memoria colectiva, en cuanto a la presencia de recuerdos que se identifican como comunes ya que se han desarrollado en similares espacios y tiempos, conjuga en el pasado un conjunto de representaciones de continuidad social, de modo que como reconstrucción parcial y selectiva de ese pasado, tiene puntos susceptibles a ser percibidos por dicha sociedad. El

\footnotetext{
Doutora em Cultura e Arte para América Latina e Caribe pela Universidad Pedagógica Experimental Libertador, Venezuela. E-mail: jenny.planificacion@gmail.com
}

Recebido em 30/08/2016 - Aprovado em 15/12/2016 http://dx.doi.org/10.5335/hdtv.17n.1.7238 
fenómeno de la memoria, según Halbwachs, existe por medio de relaciones sociales, cuyas referencias principales son el lenguaje, como palabra; el espacio, como lugar que hace posible el acontecimiento; y el tiempo, como delimitación.

[...] il y a d'une part un cadre spatial, temporel, et, plus généralement social. Cet ensemble de représentation stables et dominantes nous permet en effet, après coup, de nous rappeler à volonté les évènements essentiels de notre passé. Mais, d'autre part, il y a ce qui, dans l'impression initiale elle-même, permettrait de la situer, une fois qu'elle est reproduite, dans tel espace, tel tempe, tel milieu (HALBWACHS, 1976, p. 101). ${ }^{1}$

Esos cuadros sociales como unión de representaciones instauradas en recuerdos que se manifiestan a voluntad a nivel social, permiten la existencia, por ejemplo, de tradiciones devenidas, entre otras cosas, de la oralidad, ya que el lenguaje es un instrumento concreto que posibilita tanto su identificación como su cohesión, porque no sólo es un bien compartido, sino asimilado y aceptado, de hecho, si una persona desea entrar en un nuevo grupo social, para ser aceptada debe compartir un mismo lenguaje, "o instrumento decisivamente socializador da memoria é a linguagem" (BOSI, 1987, p. 18). No obstante, los recuerdos aunque tengan un origen individual, su entendimiento en el mundo solo es posible a través de la socialización, porque no se puede presentar como un hecho aislado, nuestros recuerdos -dice Halbwachs (1976)no se presentan como imágenes separadas, una detrás de la otra, como las perlas de un collar, porque tienen referencias externas que los ayudan a acoplarse, a organizarse incluso desde nuestras propias experiencias.
A partir de la propuesta conceptual de este teórico surge, como es lógico en todo proceso investigativo, posiciones contrapuestas dentro de las que destaca la de Joël Candau, quien asevera que la memoria colectiva es una metáfora aplicada a un determinado grupo social, pero en casos muy específicos, ya que no es posible que todos los miembros de un grupo puedan compartir totalmente las representaciones del pasado, y una de las razones podría ser el hecho de que dichos recuerdos (que constituyen la memoria colectiva) son permeados por la sociedad y la cultura, entrando a escena, entonces, la memoria social como una cantidad de recuerdos re-conocidos por el grupo, frente a la memoria colectiva en la que los recuerdos son comunes y no necesariamente re-conocidos o aceptados desde el punto de vista social (CANDAU, 2012). Ese rol de la cultura puede explicar la existencia (o construcción) de memorias "contagiadas" que se prenden en un grupo formando parte de sus recuerdos comunes, lo que no quiere decir que hayan existido, pero es importante porque desde esa experiencia comienza la construcción de elementos que caracterizan a dichos grupos, diferenciándolos de los otros, implicando una identificación de sus miembros y el nacimiento del sentido de pertenencia que surge tanto desde lo semejante como desde lo diferente, es decir, el "nosotros" frente a "los otros".

La memoria colectiva funge como una especie de vínculo para la diferenciación entre grupos sociales, donde evidentemente al ser conformados por individuos, cada uno toma para sí elementos distinguibles que tanto los lleva a relacionarse dentro del 
grupo, como los localiza frente a los demás distantes. De esta manera se conforma una suerte de identidad colectiva, que a su vez, alimenta la individual. Al hablar de este tipo de memoria, enraizada a la tradición cultural, Joël Candau (2012) devela que actúa por ejemplo, como glorificación y elogio a los héroes, al referirse concretamente a los lugares de memoria en Grecia; lo cual se podría aplicar a nuestro entorno latinoamericano en el caso de los grandes memoriales a los héroes patrios o los edificios de carácter patrimonial, todo lo cual está íntimamente relacionado con la construcción de la identidad cultural de los pueblos, tanto desde el punto de vista regional como nacional y/o local. En este sentido es interesante lo acotado por Daniel Mato cuando habla de las identidades externas e internas, siendo las primeras aquellas "imputadas al grupo", es decir, atribuidas desde otros, y las segundas, las "construidas" por ellos mismos, desde luego ambas identidades están vinculadas, no se dan por separado, sobre todo en relación al entorno y el momento histórico (2003, p. 37).

Cuando se habla de identidad se hace una relación con la identificación, ambos son conceptos que se vinculan, pues uno no puede estar aislado del otro. Las personas se identifican con algo con lo cual se sienten a gusto, pero a su vez, la sociedad les obliga a identificarse con elementos que forman parte de su contexto y entorno, así cada individuo tiene su nombre, colocado por sus padres $u$ otros mayores al nacer, luego la sociedad le impone un número de "identidad" y después se va sumando una serie de cuestiones que construyen la "identificación" de ese individuo; cuando dicha identificación es vulnerada las bases sólidas de la "identidad" del individuo tiemblan pudiendo causar rupturas serias incluso a nivel psicológico, lo que se podría llamar "crisis de identidad". ${ }^{2}$

La imposibilidad de unificación de las identidades es lo que construye las diferencias, siendo interesante el hecho de que cada una de ellas vaya siendo construida desde la perspectiva cultural de la sociedad que la crea. Ciertamente la identidad (o identidades) es algo que está en constante transformación, lo que no es otra cosa que una consecuencia normal de todo proceso humano; su dinamismo hace que cambie y que se adapte a las nuevas demandas que exigen los tiempos y las sociedades en sus emergencias. Las identidades siempre son construidas, tanto dentro como fuera de los discursos sociales y no solamente para satisfacer necesidades de auto-conocimiento y apego cultural, sino para llenar el hueco de "lo que falta" y de ese modo delinear los caminos que se deben seguir para la constitución, y este caso el rol de los edificios patrimoniales es significativo, porque son memoriales construidos "para recordar", esa es su principal función, más allá del regocijo estético desde la perspectiva del arte. Los edificios patrimoniales, el patrimonio construido, es un soporte de memoria colectiva y social.

Las identidades colectivas forman parte de las representaciones elaboradas por el individuo en la vida social, porque, como todo proceso cultural, la identidad es relacional y está identificada por símbolos que, tanto ayudan a la diferenciación como a la asimilación. Woodward (2000) expresa que la identidad está marcada por la diferencia y está precisamente en ese sentido la impor- 
tancia del edificio patrimonial para el desarrollo de la identidad de los pueblos, pues en ellos se materializa parte de la historia que ha construido la nación o región, o incluso la localidad, de acuerdo al caso.

Partiendo de todo lo expuesto, se toma la idea de las interrogantes de Louraux: ¿Es posible olvidar del todo? ¿Puede hacer un borramiento sin retorno ni huella? La marca groseramente cicatrizada de una amputación, aunque el miembro esté irremediable perdido. ¿Acaso no queda allí para recordar su ausencia? ¿O el acontecimiento de un tiempo para el duelo y la (re) construcción de la memoria? (1998), y las aplicamos en relación a los edificios patrimoniales cuando están en estado de deterioro avanzado y tanto autoridades como comunidades se deben colocar en el paredón de la decisión: ¿Qué hacer?

\section{Entre la memoria y el olvido. Rol del patrimonio construido}

En el siglo V como dictamen obligatorio, hay prohibición de recordar las desgracias, obviamente es una medida de corte político, pero con una carga social interesante ya que se lo que se busca es imprimir en la sociedad una confianza tal en sus victorias, que le permita seguir hacia la construcción de nuevos caminos hacia el logro de otros triunfos desde la auto-confianza, práctica por cierto que, aunque sin tal prohibición, aun se usa a nivel de estrategias mundiales.

Loraux (1998) relata que devenido de tal dictamen del Estado, el pueblo ateniense no soportó la continua escenificación en el teatro de las historias trágicas de su pueblo, lo que llevó, también a los dramaturgos a evitarlas, de manera que se trató en lo posible de no tocar el tema del "duelo", evitando así recordar lo triste, en una suerte de auto inducción de una amnesia construida, una supuesta no memoria social, pero solo hacia ciertos y determinados hechos, no es una verdadera inducción al olvido, es decir, en este caso podríamos hablar de "solo recordamos lo que queremos recordar". ${ }^{3}$

Este es un ejemplo que nos lleva a pensar en que el ser humano, tal como asevera Nora, de tanto querer no olvidar ha conseguido un afecto contrario. La creciente construcción de las sociedades modernas de soportes de memoria:

Si habilitásemos nuestra memoria, no tendríamos necesidad de consagrarle lugares. No habría lugares porque no habría memoria soportada por la historia. Cada gesto, hasta el más cotidiano, sería vivido como una repetición religiosa de aquello que siempre fue, en una identificación carnal de acto y de sentido (NORA, P., s/f).

Dichos soportes efectivamente, nos rodean haciendo parte hasta de nuestra vida cotidiana, tal es el caso de computadoras, celulares, pendrives, pero antiguamente ya existían otros soportes, como desde el punto de vista de la arqueología (inscripciones en cavernas, piedra, códices, frisos, petroglifos, etc.), y en otro orden el patrimonio construido (los edificios patrimoniales), memoriales para héroes patrios, e inclusive los cementerios como lugares de memoria. Entonces se llega con la modernidad y sus subsecuentes "desarrollos" culturales, sociales y económicos, a una creciente conciencia historiográfica en la que se da la debida importancia al recuerdo para las posteriores generaciones, 
incluso, de momentos e individuos que contribuyeron con la implementación de las naciones, de las independencias. No obstante, como ya sabemos, ese ser "modernos", sobre todo en la América Meridional conllevó a la suspensión del pasado, es decir, ir a un supuesto "desarrollo" significaba desechar lo "viejo" para darle paso a todo lo nuevo que estaba llegando de Europa, lo cual se verá reflejado sustancialmente en el arte, incluso inmaterial, implicando una suerte de ruptura con el pasado (ya no la prohibición o estrategia política del siglo V) para ir a la "novedad" del presente moderno. Pero más allá de esto la modernidad como autopercepción supone una relación con el tiempo, la producción de una narrativa acorde al momento y entorno en el que se desarrolla, llegando de esta manera a encontrar su sentido en la interpretación del presente.

En el siglo XX ya avanzado y el XXI se ha acrecentado un miedo al olvido, tal como acota Nora, que ha incitado a la creación compulsiva de soportes para no olvidar.

La gran mayoría de los lugares de la memoria oficial del siglo $\mathrm{XX}$ son reconocidamente nostálgico- triunfalistas -elogios de hombres famosos y celebración de famosas victorias- $\mathrm{o}$, y cada vez más, ocasiones para reconocer y recordar un sufrimiento selectivo. En este último caso, suelen ser motivo para la enseñanza de un cierto tipo de lección política: sobre cosas que se hicieron y nunca deben olvidarse, sobre errores que se cometieron y nunca deben repetirse (JUDT, 2008, p. 15-17).

En este sentido es fundamental el rol del patrimonio cultural como legado, reconocible desde la combinación de memorias $\mathrm{y}$ olvidos, que tiene un asidero imprescindi- ble para la eternización de la historia y sus procesos, en los edificios que son parte de esas narraciones entre el pasado y el presente hacia el futuro.

\section{Hacia la reutilización de los edificios patrimoniales}

En este aparte es conveniente destacar de nuevo las interrogantes tomadas de Loraux respecto a la memoria y el olvido; el preguntarse si puede hacer un borramiento sin retorno ni huella, respecto al edificio patrimonial nos lleva a entender la disyuntiva que se puede presentar tanto a nivel gubernamental, institucional como comunitario, frente a la posibilidad o necesidad de derrumbar o reutilizar un edificio patrimonial, de alto contenido de memoria histórico-socio-colectiva, implicando dicha reutilización una mudanza significativa de sus originales fines o desechando los meramente culturales. Así, desde la posición de la salvaguarda del patrimonio cultural y la misma memoria de los pueblos también cabe la analogía de Loraux de la cicatriz en el miembro amputado como un recuerdo de su existencia, ¿o no existencia?, pues ¿acaso la placa identificatoria del edificio derrumbado o reutilizado no es una suerte de cicatriz para recordar?

Es una reflexión que no se pretende responder en este breve texto, pero si dejar en el camino de la búsqueda la latente construcción de respuestas y nuevas interrogantes sobre qué hacer con el patrimonio edificado en franco deterioro, ruinas y otros afines. Pensamos, no obstante, que lo altamente peligroso estriba en el objetivo de la reutilización y dónde queda el rol cultural en si mismo. 
Solo a manera de ejemplificación tenemos la cárcel de Punta Carretas, ubicada en un barrio residencial cerca del Río de la Plata, Montevideo, Uruguay, que fuera inaugurada en el año 1910, construida según el modelo francés de Fresnes, y pasó por varios procesos: en 1931 alberga presos comunes y políticos, en 1971 guerrilleros, en 1973 pasa a ser cárcel en la dictadura, y en 1986 es clausurada por causa de un fuerte motín. Luego de varios procesos de licitación, en 1994 es inaugurado, como reutilización de edificio patrimonial, el Punta Carretas Shopping Center, un centro comercial de más de 30 mil metros cuadrados, destacando un cierto respeto al estilo original interno de la cárcel tipo Frenes, pero cambiando totalmente el sentido cultural de un espacio de memoria histórica.

Otro ejemplo también en Uruguay, es el Penal de Miguelete, inaugurado en el año 1888, y que fuera reclusorio de presos de delitos menores, después penal para menores de edad, hasta el cierre de sus puertas en 1986: En 2008 el gobierno nacional de dicho país resolvió comenzar a alojar allí las instalaciones del Centro Cultural Espacio de Arte Contemporáneo (EAC), aunque con francas mudanzas en la arquitectura de dicho lugar de memoria.

En México destacamos la experiencia de la Penitenciaría de San Luis Potosí, cuya construcción inició en febrero de 1884, siendo inaugurado, aún sin concluir, el 5 de mayo de 1890 y terminado en 1904. En el año de 1910 ocurrió un hecho histórico, ya que el general Porfirio Díaz ordenó que se apresara a Francisco I. Madero por los cargos de conato de rebelión y ultraje a las autoridades, y fue trasladado a la entonces penitenciaría de San Luis Potosí. (lo cual es un hecho pre- ámbulo a la Revolución Mexicana). El edificio fue utilizado como centro penitenciario hasta marzo de 1999. Luego de una serie de licitaciones se crea el Centro de Artes de San Luis Potosí, respetando no solo el hecho cultural de este lugar de memoria, sino en su mayoría la construcción original y el estilo Frenes de la arquitectura, estando las oficinas en las antiguas celdas y sirviendo incluso de sala de exposiciones.

Figura 1: Exposición de ropa de diseñador

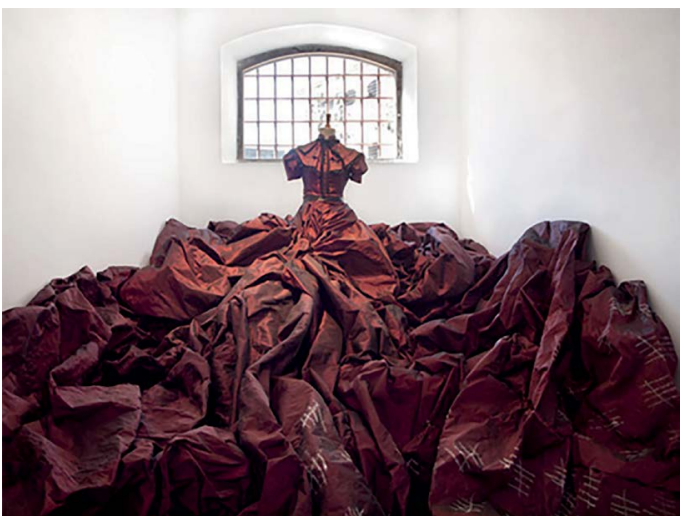

Fuente: acervo de la autora.

Figura 2: Vista interna donde destaca la construcción original restaurada y la inserción de lo moderno

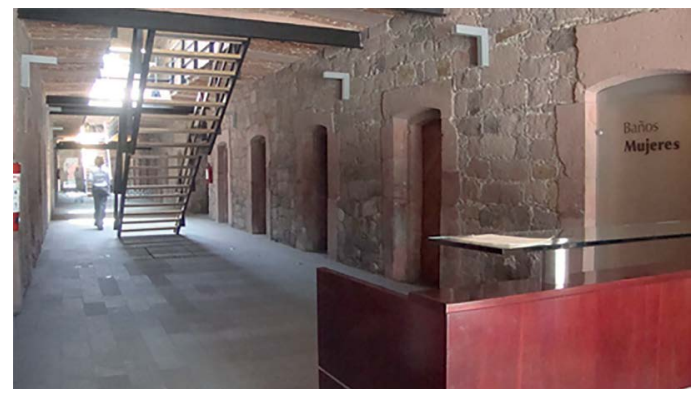

Fuente: acervo de la autora.

En los casos ejemplificados se ha visto un nuevo uso de dichos edificios $y$, cabe destacar en cada uno existe la placa como memorial 
del espacio original, de una u otra manera aún perviven, pero ¿qué hubiera pasado si hubiesen sido destruidos? Tal vez se hubiese perdido una buena parte de la historia que cuentan, pero cabe siempre la duda, sobre todo en lo que respecta al citado centro comercial.

El escritor venezolano José Ignacio Cabrujas, siempre ocupado por el bienestar memorial de Caracas expresa que la frágil identidad de la urbe con incidencia en sus habitantes, se debe al afán heredado de la modernidad y su falsa concepción de "desarrollo", por derrumbar todo vestigio del pasado.

La sensación era tumbar y tumbar, edificar y edificar, pero sin que las personas que edificaran allí, en ningún momento, pensaran en la permanencia de los sitios. Por lo tanto para mí es fácil ahora decirlo; que Caracas es una ciudad provisional; que Caracas está construida sobre la base de una vieja manera de hablar de los caraqueños, de una vieja tradición caraqueña, que es "mientras tanto" y "por si acaso" (CABRUJAS apud GONZÁLEZ, 2008, s/p).

Según González (2008) tal destrucción del pasado no era un fenómeno casual, pues el conseguir llegar a la eliminación o transformación radical del entorno y la historia obedece a estrategias discursivas que buscan minimizar el valor de la naturaleza, el patrimonio edificado, el pasado indígena, la presencia africana de los esclavizados, es decir, la Historia del país desde su núcleo social, más allá de lo meramente teórico, todo lo cual conlleva a la merma de la identidad cultural nacional.

En Caracas, Venezuela, tenemos ejemplos de reutilización de edificios patrimoniales como es el caso del Teatro Ayacucho que data de 1925, cuando fuera centro artístico que albergaba aproximadamente 1.300 espectadores. En 1990 se le hace una intervención para convertirlo en un pequeño centro comercial y cine; luego en 1994 es declarado Monumento Histórico Nacional y continua teniendo la misma función comercial. Esta reutilización y declaratoria no ha respetado la arquitectura original del lugar de memoria, salvo en la fachada.

Figura 3: Fachada Teatro Ayacucho.

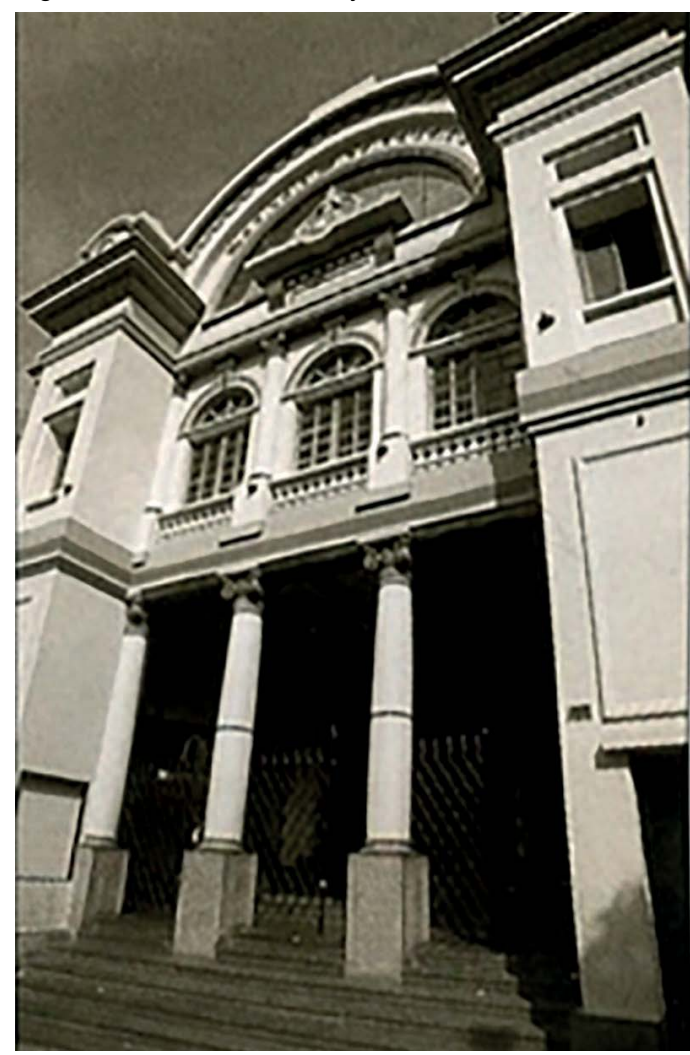

Fuente: Monumentos históricos nacionales, IPC, s/f, p. 64

También en Venezuela, pero en la ciudad de Maracaibo, estado Zulia, encontramos en el Centro de Arte de Maracaibo Lía Bermúdez, que ha tenido varias funciones. En 1816 se inaugura como el primer Mercado 
Público de Maracaibo. Sufriendo un incendio en 1927 se reinaugura en 1931 con intervenciones. En 1973 cierra sus puertas como mercado. Entre 1978 y 1982 funge como Centro Popular de Cultura, y en 1990 se convierte en el Centro de Arte de Maracaibo Lía Bermúdez, teniendo su apertura formal en 1993 siguiendo así hasta los momentos.

Figura 4: Centro de Arte de Maracaibo Lía Bermúdez

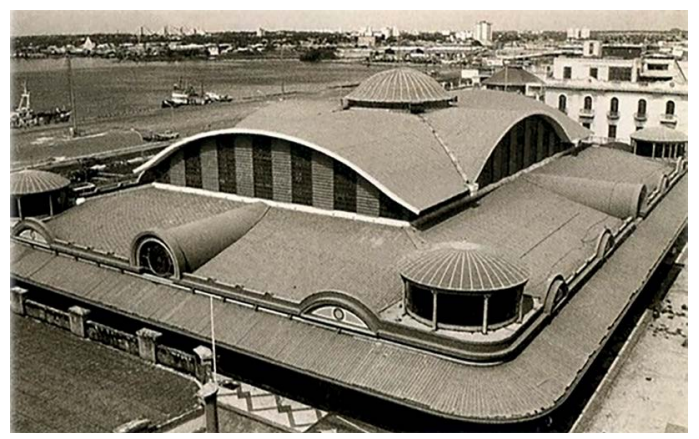

Fuente: Monumentos históricos nacionales, IPC, s/f, p. 53.

Este edificio patrimonial tiene la placa memorial de identificación y tiene un carácter cultural que permite la continuidad de trabajos en materia de investigación, salvaguarda, promoción y difusión de la historia de la región. ¿Qué hubiese pasado si el viejo mercado incendiado hubiera sido derrumbado?

\section{Hacia la salvaguarda y protección de los edificios patrimoniales}

Con todo lo expuesto a lo largo de estas líneas abogamos por la salvaguarda del patrimonio cultural tanto material como inmaterial, y concretamente en lo que a edificios se refiere, antes de derrumbar es conveniente hacer los estudios pertinentes que no solo son aquellos relacionados con la parte mera- mente técnica, pues el rol de la comunidad a la que pertenece tal construcción, tanto desde el punto de vista histórico-cultural como memorial-social (que implica lo afectivo), es fundamental para la toma de decisiones en torno al destino de la preservación física de los lugares de memoria.

La experiencia francesa en la materia es ampliamente reconocida por su aptitud para analizar la especificidad de un sitio, de su historia, de su entorno cultural, y para proponer medidas adecuadas a cada caso destinadas a preservar su valor patrimonial, asegurando al mismo tiempo su adaptación a las necesidades y usos contemporáneos (CARRIÓN, 2001, p. 25).

Tal adaptación a necesidades y usos contemporáneos de la que habla Carrión debería estar también acorde a las nuevas perspectivas sociales desde la identidad y el sentido de pertenencia hacia los patrimonios, pues calles, edificios, plazas, en fin, lugares, materialidades que llevan hacia el recordar, son parte constitutiva de nuestra memoria social, colectiva e histórica. Así cada espacio público que se pretenda recuperar para su reutilización debe ser concebido para el disfrute social, sin dejar de lado su importancia como lugar de memoria, o sea, que siga siendo el soporte para recordar lo que hubo allí en un pasado, aunque no fuere del todo alegre, como en el caso de cárceles, hospitales, etc.

Para finalizar, seguimos con las interrogantes para la reflexión sobre el rol del patrimonio edificado y la responsabilidad que Estado, organizaciones, instituciones y comunidades tenemos para la salvaguarda, protección y conservación de los lugares de memoria. ¿Qué hacer con el patrimonio edi- 
ficado, cuando ya no se le puede dar el uso para el cual fue creado? ¿Se debe dejar tal cual, aunque se corra el riesgo de perderlo? ¿Se le debe dar otro uso, incluso no vinculado con el arte o la continuidad de su memoria, lo cual podría traer consigo una suerte de desvirtualización de su originalidad?

\section{Resumo}

O presente artigo objetiva levar o leitor a refletir sobre a reutilização dos edificios patrimoniais, visto que esses são lugares detentores de memória histórica e coletiva da sociedade a que pertecem. Com exemplos específicos, em caso de países como o Uruguai, México e Venezuela, se desenvolve uma breve análise sobre os convenientes e inconvenientes da intervenção na arquitetura original dos edificios - lugares de memoria - para levar a cabo novas perspecivas de uso, muitas das quais nem sempre vinculadas ao cultural. Tais ações atingem a identidade e o sentido de pertencimento da comunidade para com os edificios. Destaca-se, também, a salvaguarda, conservação e proteção dos edificios patrimoniais como lugares de memória.

Palavras-chave: Lugares de memoria. Memória. Novos usos. Patrimônio Material.

\section{Abstract}

This article intends to take the reader to the reflection on the reuse of heritage buildings being these places of memory as much historical as collective and social, of the towns to which they belong. With specific examples in cases of countries such as Uruguay, Mexico and Venezuela, a brief analysis is developed on the appropriateness or not of the intervention of the original architecture of the buildings as places of memory to continue then plans of new perspectives of use many of the which are not always linked to the cultural area, which points to a sort of aggression to the identity and sense of belonging of the community to these buildings. It is also advocated for the safeguarding, conservation and protection of heritage buildings, places of remembrance.

Keywords: Memory. Material heritage. New uses. Places of Memory.

\section{Notas}

1 “[...] hay por un lado, un cuadro espacial temporal, y generalmente más social. Esta yuxtaposición de representaciones estables y dominantes nos permiten, en efecto, recordar a voluntad los acontecimientos esenciales de nuestro pasado. Pero, por otra parte, dentro de la misma impresión inicial, nos permitiría situarla, una vez que es reproducida, dentro de tal espacio, tal tiempo, tal medio" (Traducción de la autora).

2 En los campos de concentración nazis de comienzos del siglo XX los judíos prácticamente perdían su identidad al ser "borrados" sus nombres siendo sustituidos por un número de código que era tatuado en el cuerpo. En el siglo XXI los sionistas israelíes han implementado destruir mapas que identifiquen ciertos lugares como tierras palestinas, han quemado libros de historia de Palestina, y hacen continuamente una serie de acciones relacionadas con el "borrar" elementos que forman parte de la identidad palestina, inclusive en actas de nacimiento, etc. Menos traumático el caso, pero no por ello menos ejemplificable, es el hecho específico de la autora de este trabajo quien se ha tratado de adaptar a un cambio de nombre en Brasil, ya que en su país de origen se acostumbra primero colocar el apellido paterno y luego el materno, siendo que en Brasil es al contrario, lo cual le ha causado (muchas veces inconscientemente) un problema de "identidad". 
Respecto a esto cabe destacar lo que asevera Daniel Mato, cuando expresa que "“La identidad cultural no es estática, sino que se transfigura y transforma permanentemente, incorporando nuevos elementos y/o modificando los anteriores [...] Cabría decir, incluso, que ella no sólo no es estática, sino que es en sí misma social y eventualmente conflictiva", (2003, pp. 98-99)

3 Este nos lleva a pensar en la tesis de San Agustín sobre el repositorio de memoria, y que el hombre no olvida, sino que guarda en esa especie de armario lo que no quiere recordar, pero no lo olvida, está allí pero no a la mano. Para ahondar más en el tema sugerimos leer Confesiones XI.

\section{Referencias}

BOSI, Eclea. Memória e Sociedade: Lembranças de velhos. São Paulo: T.A. Quieroz, 1987.

CANDAU, Joël. Memória e Identidade. Traducido por Maria Leticia Mazzucchi Ferreira. São Paulo: Contexto, 2012.

CARRIÓN, Fernando. (Org.) Centros Históricos de América Latina y El Caribe. Ecuador: UNESCO, 2001.

FERNANDES MELO, Sabrina. Patrimônio, arquitetura e estética urbana em Florianópolis a partir de 1930. Revista Mouseion, Unilasalle, v. 1, n. 12, p. 105-117, maio/ago. 2012.

GONZÁLEZ, Lorenzo; MARÍN, Orlando. Tiempos superpuestos: arquitectura moderna e "indigenismo" en obras emblemáticas de la Caracas de 1950. Revista de Estudios sobre Patrimonio Cultural - Journal of Cultural Heritage Studies. Bogotá, Orlando, v. 21, n. 2, p. 266-279, 2008.

HALBWACHS, Maurice. Les cadres sociaux de la mémoire. Paris: Mouton, 1976.

HALL, Stuart. Quem precisa da identidade? In: DA SILVA Tomas Tadeu (Org.) Identidade $e$ Diferença. A perspectiva dos Estudos Culturais. Trad. Tomas Radeu DA SILVA. Petrópolis: Vozes, 2000.
JUNG, Carl Gustav. Símbolos de transformación. Barcelona: Paidós, 1963.

LORAUX, N. De la amnistia y su contrario. In: YERUSINOMI, Y. (Coord.) Usos del Olvido. Buenos Aires: Nueva Visión, 1998.

MATO, Daniel. Crítica de la modernidad, globalización y construcción de identidades. Caracas: UCV, 2003.

MORENO, J. Monumentos históricos nacionales. Caracas: IPC., s/f.

NORA, P. Entre História e Memória. A problemática dos lugares. In: NORA, P. (Org.) Les lieux da mémoire. 1 La République. Paris: Gallimard, 1984.

RILLA, José. Memorias y Patrimonios del Pasado Reciente. In: Revista Memoria em Rede. UfPel, 2012. Disponible en: <https://periodicos.ufpel.edu.br/ojs2/index.php/Memoria>. Acesso em 10 jan. 2017.

WOODWARD, Kathryn. Identidade e diferença: uma introdução teórica e conceitual. In: DA SILVA, Tomas Tadeu (Org.) Identidade e Diferença. A perspectiva dos Estudos Culturais. Petrópolis: Vozes, 2000. 